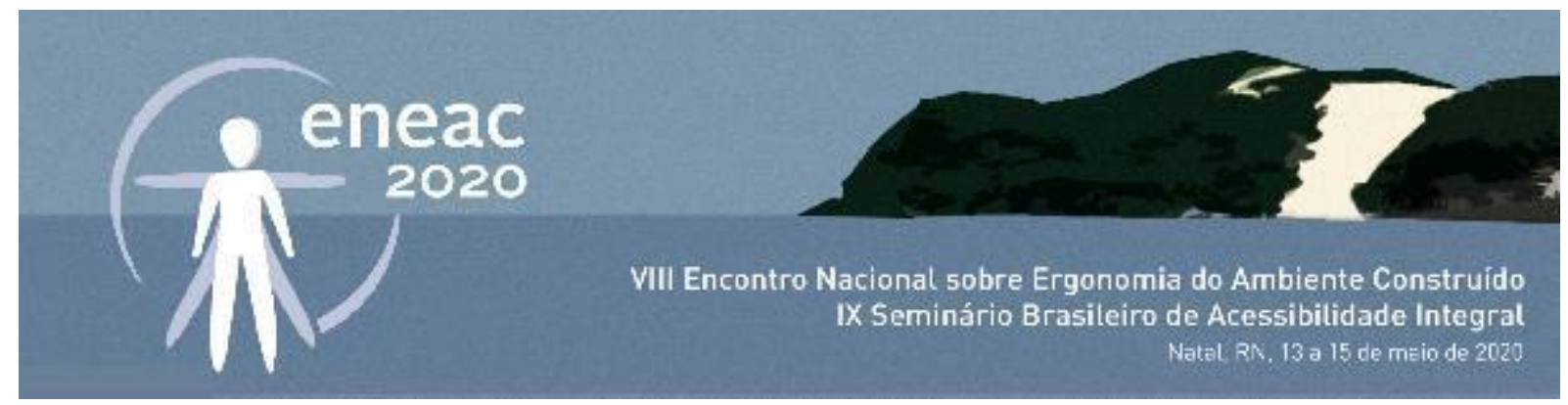

\title{
Avaliação de acessibilidade espacial no centro de Santa Maria
}

\author{
Spatial Accessibility evaluation in Santa Maria downtown
}

\begin{abstract}
VANESSA GOULART DORNELES
Doutora em Arquitetura e Urbanismo, Universidade Federal de Santa Maria, arq.vanessadorneles@gmail.com

MARIA LUISA SCHARLAU DA SILVA

Graduanda em Arquitetura e Urbanismo, Universidade Federal de Santa Maria, marialuisascharlau@gmail.com

CAMILA OSVALD

Graduanda em Arquitetura e Urbanismo, Universidade Federal de Santa Maria, camiosw@gmail.com

MARIANA MIOLO DE FREITAS

Graduanda em Arquitetura e Urbanismo, Universidade Federal de Santa Maria, miolomarianaa@gmail.com
\end{abstract}

SILVIA FARIAS

Mestranda em Arquitetura, Urbanismo e Paisagismo PPGAUP-UFSM, Universidade Federal de Santa Maria, sisilviafarias@gmail.com

LUIS GUILHERME AITA PIPPI

Doutor em Arquitetura e Urbanismo, Universidade Federal de Santa Maria, guiamy@hotmail.com

\section{RESUMO}

A apropriação dos espaços abertos nas cidades médias brasileiras é uma das preocupações dos urbanistas que intencionam manter a vitalidade dos centros urbanos. Acredita-se que a apropriação destes espaços pode ser garantida através de boas condições de acessibilidade espacial. Este artigo se propõe a avaliar as condições de acessibilidade nos espaços abertos do Centro da Cidade de Santa Maria. Através do estudo dos conceitos relacionados à acessibilidade e da análise de como ocorre a utilização dos espaços, será possível compreender as dificuldades do meio, sob a ótica dos usuários. Nesta pesquisa, foram utilizados três métodos de avaliação do espaço: inventário ambiental, a fim de reconhecer elementos que proporcionam ou não acessibilidade, entrevistas, para saber como os 


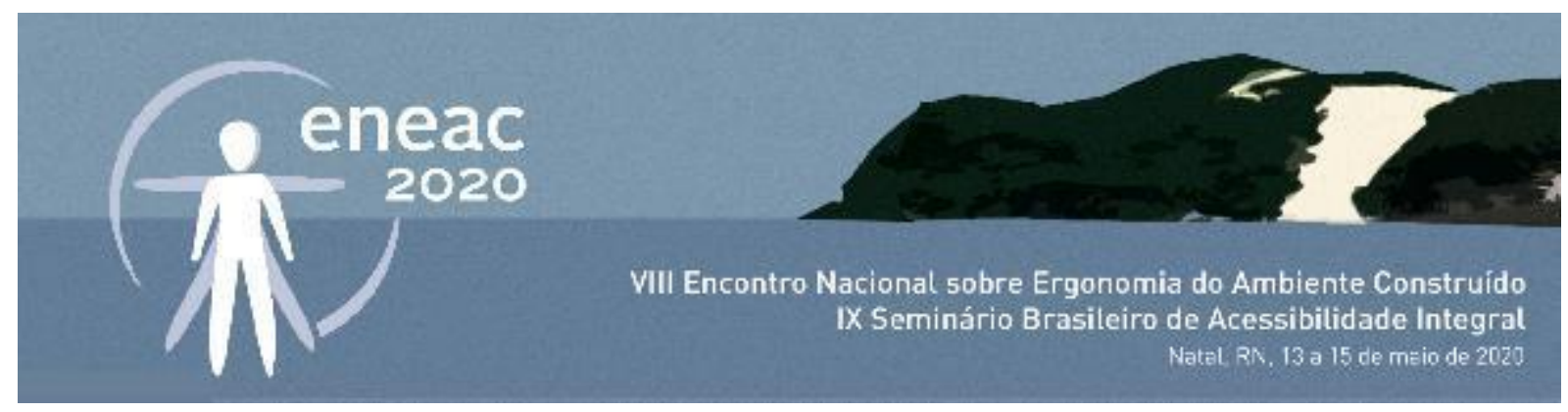

usuários percebem o local e suas necessidades e, por fim, o passeio acompanhado, para observar como uma pessoa com deficiência ou restrição utiliza o local. É importante entender que a acessibilidade nesses espaços é fundamental para que ocorra maior integração e melhor utilização dos mesmos. Através da avaliação dos espaços abertos, tem-se um diagnóstico para melhorá-los e, assim, ter uma cidade mais democrática.

PALAVRAS-CHAVE: Arquitetura e Urbanismo, Acessibilidade especial, Espaços Abertos

\section{ABSTRACT}

The appropriation of open spaces in medium-sized Brazilian cities is one of the concerns of urban planners who intend to maintain the vitality of urban centers. It is believed that the appropriation of these spaces can be guaranteed through good conditions of spatial accessibility. This article aims to evaluate the conditions of accessibility in the open spaces of the Center of the City of Santa Maria. Through the study of concepts related to accessibility and the analysis of how people use these spaces, it will be possible to understand the difficulties of the environment, by the optics of the users. In this research, three methods of evaluation were used: environmental inventory, to recognize elements that provide or not accessibility; interviews with users, to know how people perceive the place and what are their needs and the accompanied walk, to observe how a person with deficiency or restriction uses the place. It's important to understand that accessibility is fundamental to provide integration and the use of these spaces. Through the evaluation of open spaces, there is a diagnosis to improve them and, thus, have a more democratic city.

KEYWORDS: Architecture and Urbanism, Spatial Accessibility, Open Spaces

\section{INTRODUÇÃO}

O estudo da relação pessoa e ambiente permite um entendimento melhor das necessidades espaciais das pessoas nos ambientes existentes e servem para embasar novas ações de projeto e políticas públicas em prol de uma melhor apropriação dos espaços.

Entende-se o conceito de apropriação quando o sujeito "[...]se projeta no espaço e o transforma em um prolongamento de sua pessoa, criando um lugar seu[...]" (CAVALCANTE; ELALI, 2017, p.63). Além disso, "[...] na noção de apropriação estão implícitas a ideia de adaptação de um espaço a um uso definido pela pessoa, assim como as ações que ela implementa para a obtenção deste fim."(CAVALCANTE; ELALI, 2017, p. 68).

Dessa forma, uma preocupação que se tem com a qualidade dos espaços abertos e sua ambiência é a suas condições para apropriação, pois para se manter sua vitalidade é preciso que as pessoas os utilizem e possam desenvolver sentimentos de apego pelo lugar. A ambiência de um lugar tem relação com o modo como as pessoas se comportam, pois, a maneira como o espaço é percebido cria diferentes sentimentos (CAVALCANTE; ELALI, 2018).

Acredita-se que as condições de acessibilidade espacial influenciam sobremaneira esta apropriação, pois é necessário condições físicas para acesso e uso. Um espaço sem acessibilidade acaba por interferir na interação das pessoas com o ambiente e com outros usuários do local. Assim, este artigo 


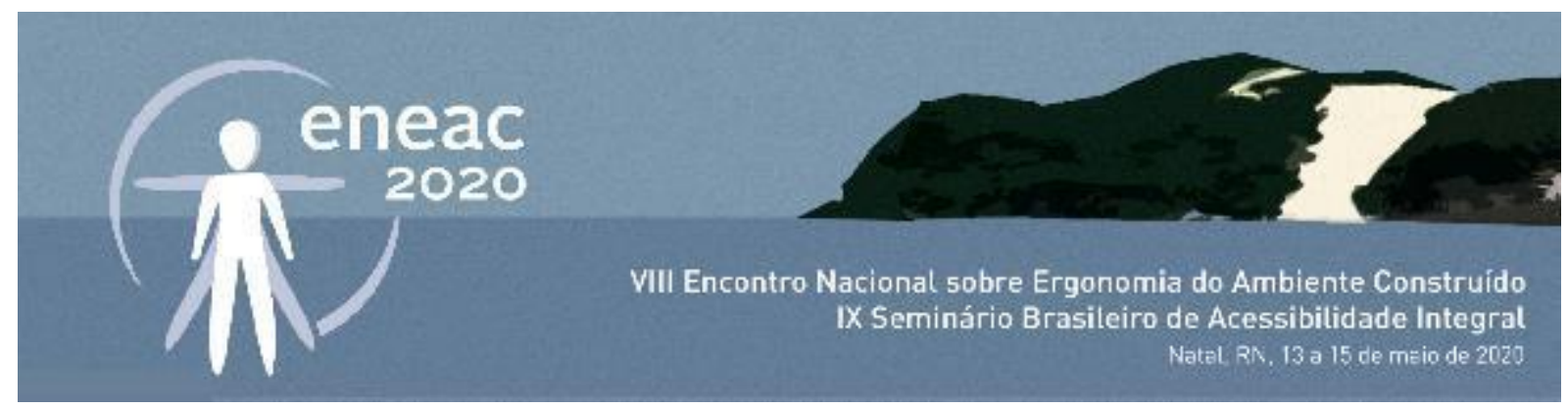

busca analisar a acessibilidade nos espaços abertos do centro do município de Santa Maria-RS. 0 desenvolvimento deste trabalho conta com um breve referencial a cerca do tema acessibilidade e posteriormente apresenta o estudo de caso. $O$ estudo de caso foi desenvolvido na região central da cidade que engloba duas praças e o Calçadão da cidade e contou com a aplicação de três métodos: inventário ambiental, entrevistas e passeio acompanhados. Ao final do artigo apresenta-se a conclusão do estudo com o diagnóstico da área estudada.

\section{REFERENCIAL TEÓRICO}

Desde a Constituição Brasileira de 1988 (BRASIL, 2016), já é previsto que todos os cidadãos tem direitos de acesso a moradia, educação, saúde e trabalho sem discriminação. A acessibilidade garante que as pessoas tenham acesso a espaços e possam utilizá-los sem dificuldades. Porém, além da acessibilidade, é importante pensar na inclusão social como uma peça fundamental para que todas as pessoas possam participar e usufruir democraticamente da vida na cidade e seus espaços abertos. Entende-se como espaços abertos ou livres, no contexto urbano, todos aqueles espaços sem edificação que são destinados ao lazer ou ao deslocamento das pessoas, como as ruas, praças, largos, pátios, quintais, parques, jardins, etc. (MACEDO, 1995).

Além da acessibilidade, existe um conceito mais abrangente - desenho universal - que vem tomando mais importância desde a década de 1960, com o fim da Segunda Guerra Mundial. O Desenho Universal consiste numa filosofia de projeto que visa a igualdade de acesso e uso para a maior gama possível de usuários (MACE, 1985), e deve estar presente no processo projetual de arquitetos e designers (DORNELES, 2014).

Enquanto a acessibilidade segue normativas como a ABNT NBR 9050, a fim de adaptar locais para garantir o acesso de pessoas com deficiências ou restrições, o desenho universal já pensa espaços inclusivos através de ações de projeto que conciliam as diversas necessidades (ASSOCIAÇÃO BRASILEIRA DE NORMAS TÉCNICAS ABNT, 2015). Assim, é preciso reconhecer "que as pessoas são naturalmente diferentes" (DISCHINGER; BINS ELY; PIARDI, 2013, p. 16), compreender suas necessidades espaciais e eliminar ou minimizar as ações das barreiras arquitetônicas ou mesmo atitudinais.

Para garantir uma acessibilidade satisfatória é preciso conhecer seus quatro componentes, são estes: a orientação, a comunicação, o deslocamento e o uso. A orientação permite aos "indivíduos reconhecer a identidade e as funções dos espaços" (DISCHINGER; BINS ELY; PIARDI, 2013, p. 29). A comunicação se refere à relação entre usuários ou à obtenção de informações através de equipamentos existentes no local. O deslocamento é a "possibilidade de qualquer pessoa poder movimentar-se ao longo de percursos horizontais e verticais" (DISCHINGER; BINS ELY; PIARDI, 2013, p. 30). E o uso corresponde à participação e utilização de atividades e equipamentos, respectivamente, no local (DISCHINGER; BINS ELY; PIARDI, 2013). 


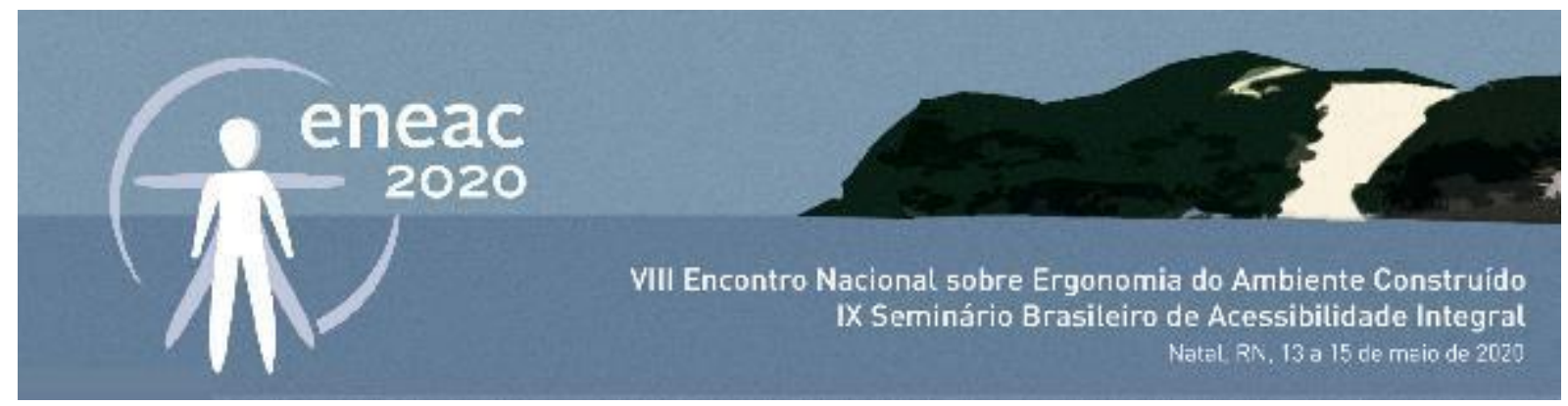

Essa pesquisa foi desenvolvida sob a ótica da acessibilidade, pois avalia espaços abertos existentes na cidade de Santa Maria, para dar suporte para projetos para melhoria dos espaços que aí sim irão considerar a filosofia do desenho universal.

\section{ESTUDO DE CASO E MÉTODOS}

O estudo de caso refere-se aos espaços abertos da cidade de Santa Maria (Rio Grande do Sul, Brasil), especificamente no calçadão da cidade e suas áreas adjacentes de grande valor histórico e comercial - Praça Saldanha Marinho, Segunda e Terceira quadras da Rua Doutor Bozzano e Praça Saturnino de Brito (figura 1), as quais concentram grande fluxo de pessoas no cotidiano e, na busca de garantir acesso com inclusão nesta área, viu-se necessário uma avaliação física do local e de suas atuais condições de acessibilidade.

Figura 1 - Imagem aérea da área de estudo (Praça Saldanha Marinho, Calçadão, duas quadras da Rua Doutor Bozzano e Praça Saturnino de Brito)

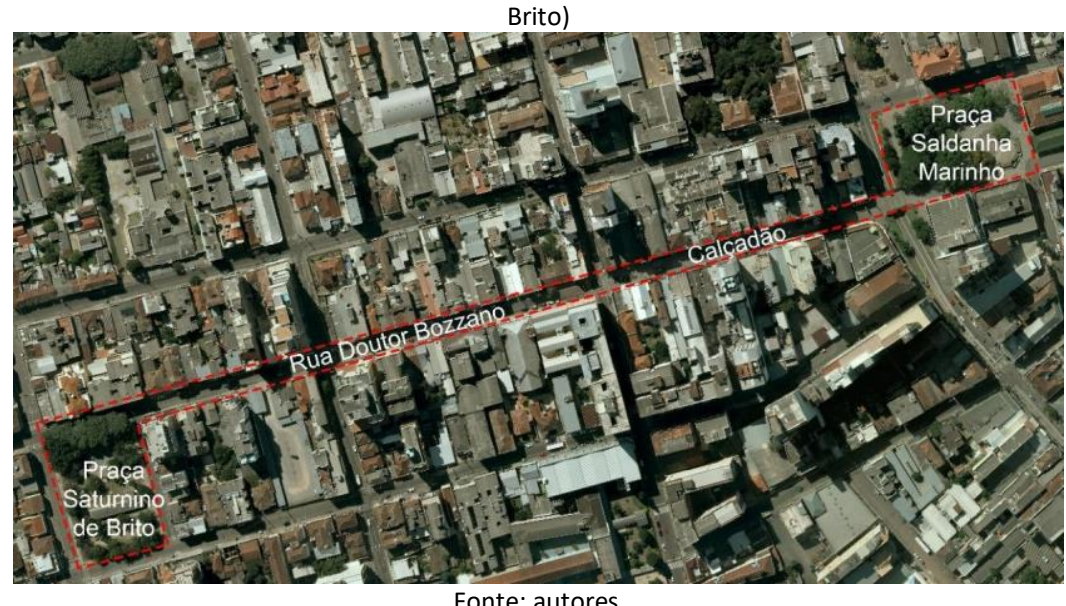

Para a avaliação física do local, optou-se pela utilização de três métodos, sendo que dois contaram com auxílio dos usuários, a fim de compreender de forma sucinta suas reais necessidades no espaço público de Santa Maria. Os métodos utilizados foram: o inventário ambiental com objetivo de reconhecer os elementos existentes que proporcionam ou não acessibilidade; entrevistas, a fim de compreender as necessidades e desejos dos usuários frequentes e ocasionais; e, passeios acompanhados com pessoas com alguma deficiência ou limitação, a fim de perceber suas dificuldades reais no espaço.

O primeiro método - o inventário ambiental - consiste em uma avaliação pós ocupação do espaço (APO). Esta antecede a todos levantamentos e/ou análises, por fornecer uma visão ampla e geral sobre o desempenho do espaço e de seus usos. Teve como base em Fichas de Inventário Ambiental, elaboradas por Mendonça, Blower e Páscoa (2006), por meio dos quatro eixos de avaliação (estéticocompositivo, técnico-construtivo, contextual ambiental e, pragmático ambiental), identificar e até hierarquizar os problemas que necessitam de maior aprofundamento e os aspectos positivos que possam ser evidenciados. 


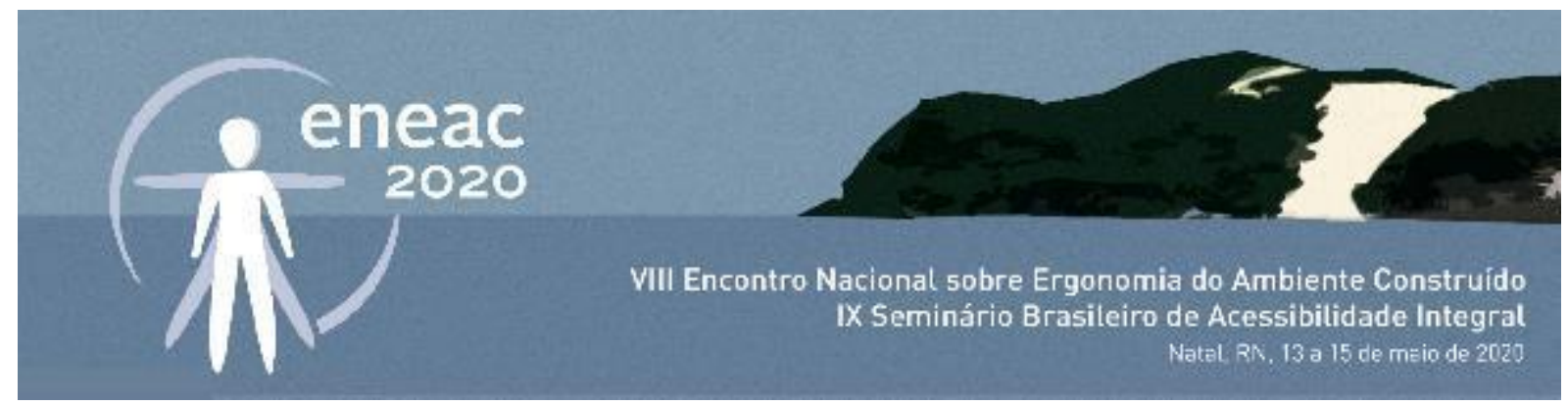

Figura 2 - Modelo de ficha de Inventário Ambiental.

\begin{tabular}{|c|c|}
\hline "Acessibili & $\begin{array}{l}\text { Universidade Federal de Santa Maria } \\
\text { Centro de Tecnologia | Curso de Arquitetura e Urbanismo } \\
\text { PARQUI - Laboratório de Paisagem, Arquitetura e Imaginário } \\
\text { idade espacial em espaços abertos urbanos: o caso do calçadão de Santa Ma }\end{array}$ \\
\hline \multicolumn{2}{|r|}{ FICHA DE INVENTÁRIO AMBIENTAL - ESPAÇOS LIVRES PÚBLICOS } \\
\hline \multicolumn{2}{|r|}{ Pesquisadores em campo: } \\
\hline \multicolumn{2}{|l|}{ Setor de análise:- } \\
\hline Tipo: & Análise: \\
\hline \multicolumn{2}{|l|}{ PISO } \\
\hline \multicolumn{2}{|l|}{ VEGETAÇÃO } \\
\hline \multicolumn{2}{|l|}{ MOBLLÁRIO } \\
\hline \multicolumn{2}{|l|}{ USUÁRIOS } \\
\hline \multicolumn{2}{|l|}{ ATIVIDADES } \\
\hline \multicolumn{2}{|l|}{ PERCURSOS } \\
\hline \multicolumn{2}{|l|}{ ILUMINAÇÃO } \\
\hline \multicolumn{2}{|l|}{ ACÚSTICA } \\
\hline \multicolumn{2}{|l|}{ SENSAÇÕ TÉRMICA } \\
\hline \multicolumn{2}{|r|}{ FGGURA OL: FICHA DE INVENTÁRIO AMBIENTAL } \\
\hline & \multirow{3}{*}{ 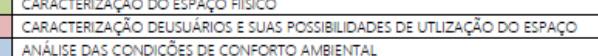 } \\
\hline & \\
\hline & \\
\hline
\end{tabular}

Fonte: autores.

O segundo método - a entrevista- "[...]é uma das principais técnicas de trabalho em quase todos os tipos de pesquisa utilizados nas ciências sociais[...]"(LÜDKE; MARLI, 1986, p.33). Consiste em um roteiro de perguntas com finalidade de obter informações desejadas referentes ao assunto da pesquisa. Sua vantagem, segundo Lüdke e Marli (1986), é a obtenção das informações e possíveis correções imediatamente. As entrevistas realizadas possuem 8 questões, referentes aos espaços da pesquisa, tendo duração média de 5 minutos e consistiram em uma pesquisa qualitativa.

1. Com que frequência você vem ao centro da cidade?;

2. O que você acha do centro de Santa Maria?;

2.a) Aponte aspectos positivos deste lugar.;

2.b) Aponte aspectos negativos deste lugar.;

3. A aparência do calçadão é: ( ) muito boa, ( )boa, ( )nem boa, nem má, ( )ruim, ( )muito ruim;

4. Qual espaço você mais gosta no centro?

5. Qual sentimento este espaço te provoca?

6. Qual/quais atividades você faz neste lugar?;

7. Qual/quais atividades você gostaria de fazer neste lugar?;

8. O que você acha que poderia ter neste lugar para poder fazer essas atividades? 


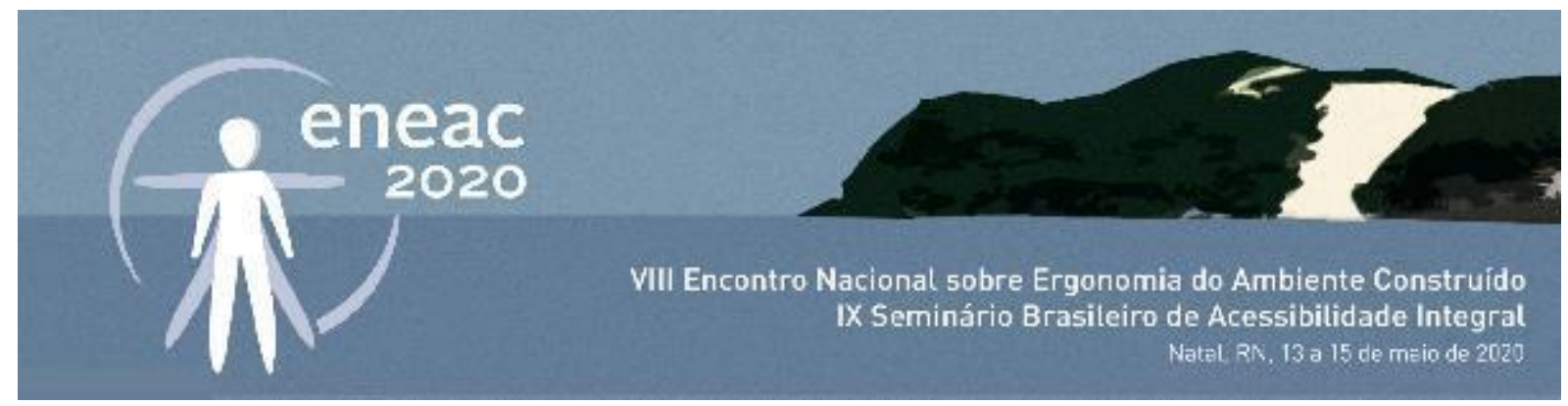

Após essas perguntas, foi criado um perfil dos entrevistados, a partir de 3 perguntas sobre o gênero, a faixa etária e a escolaridade destes.

O terceiro método utilizado foi o passeio acompanhado. Este, baseia-se em observar uma pessoa utilizando espaços pré-determinados dentro da área de estudo, a fim de visualizar suas decisões e, compreender, quais dificuldades e facilidades encontradas para exercer essas atividades (DISCHINGER, 2000).

Nesse método, foram realizados quatro passeios, com uma pessoa em cadeira de rodas, uma pessoa surdo-muda, uma pessoa cega e um idoso. Nestes passeios foram propostas sete atividades diluídas no perímetro de estudo, exemplificado na ficha de acompanhamento abaixo, que mostra o percurso, e numera os ambientes ou equipamentos que deveriam ser utilizados durante os passeios acompanhados (ver figura 2).

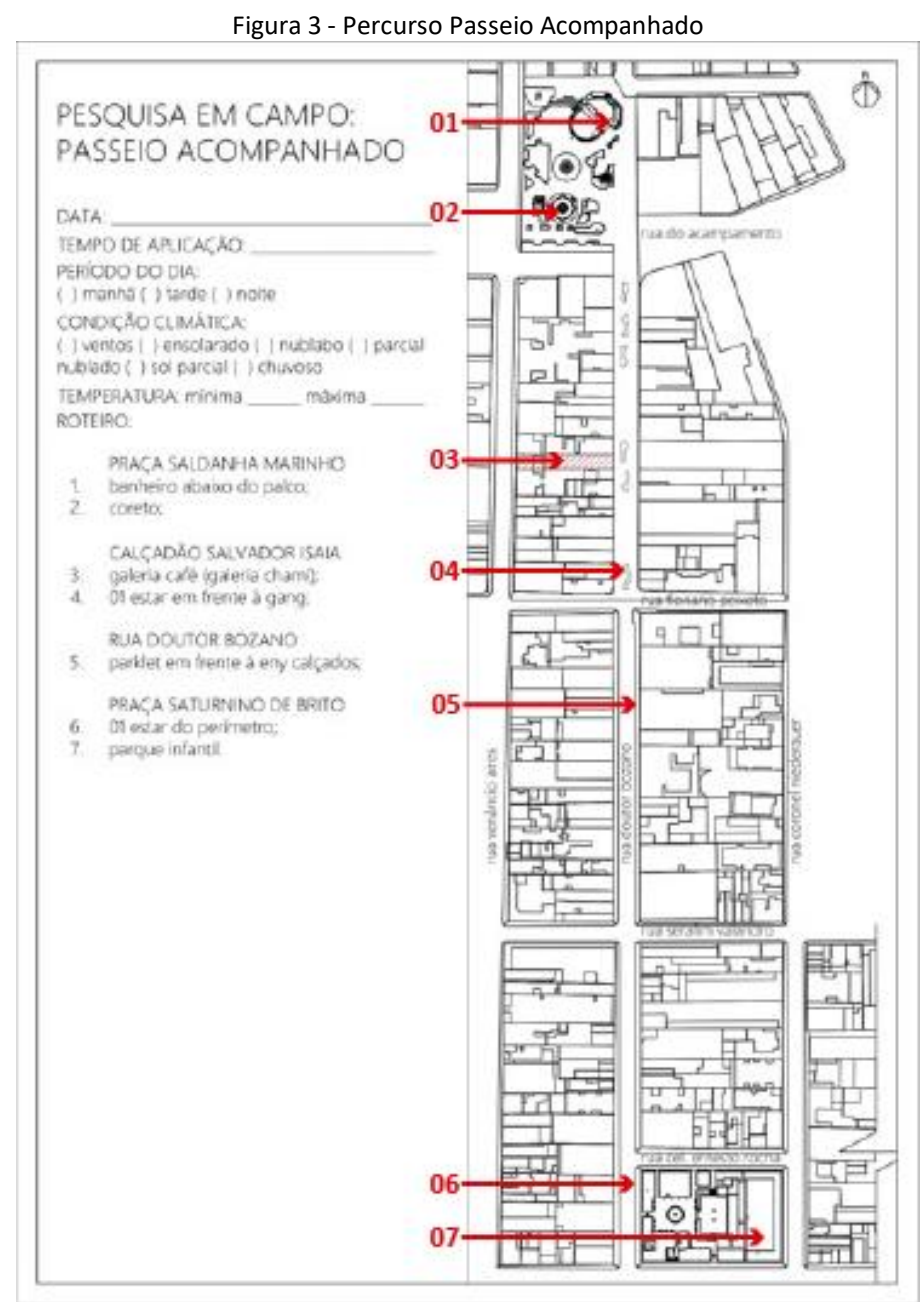

Fonte: Autores 


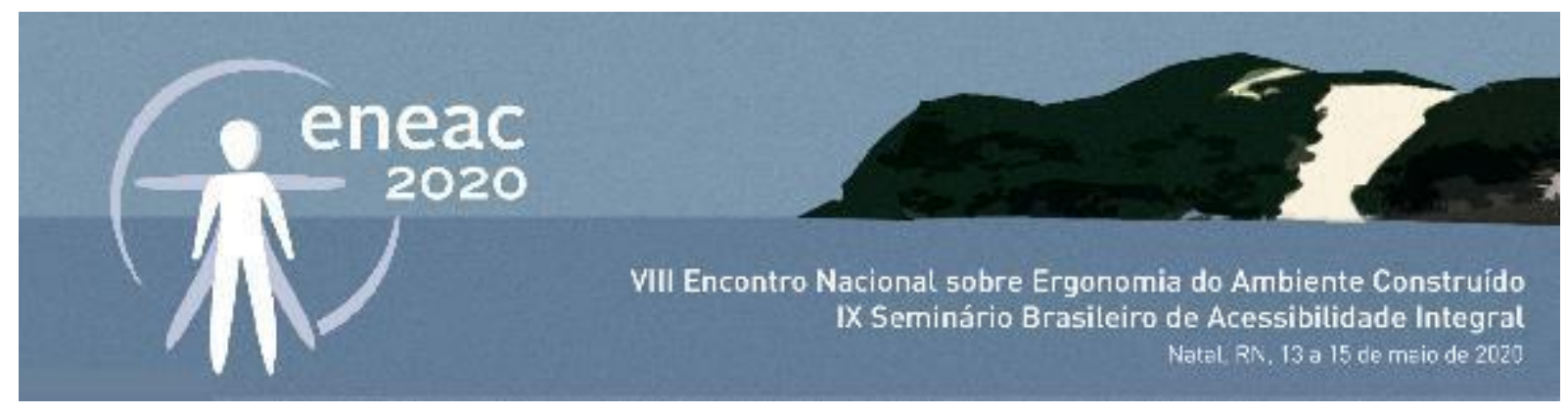

\section{RESULTADOS}

A seguir apresenta-se os resultados dos três métodos utilizados:

\section{Inventário ambiental}

No primeiro método, o inventário ambiental, notou-se a irregularidade de materialidade e pouca conservação do piso (figura 3), criando espaços que não permitem fluidez na locomoção, com excessivas barreiras; pouca ou inexistente sinalização inclusiva; rampas de entrada em passeios sem as mínimas condições de uso adequado (figura 4).

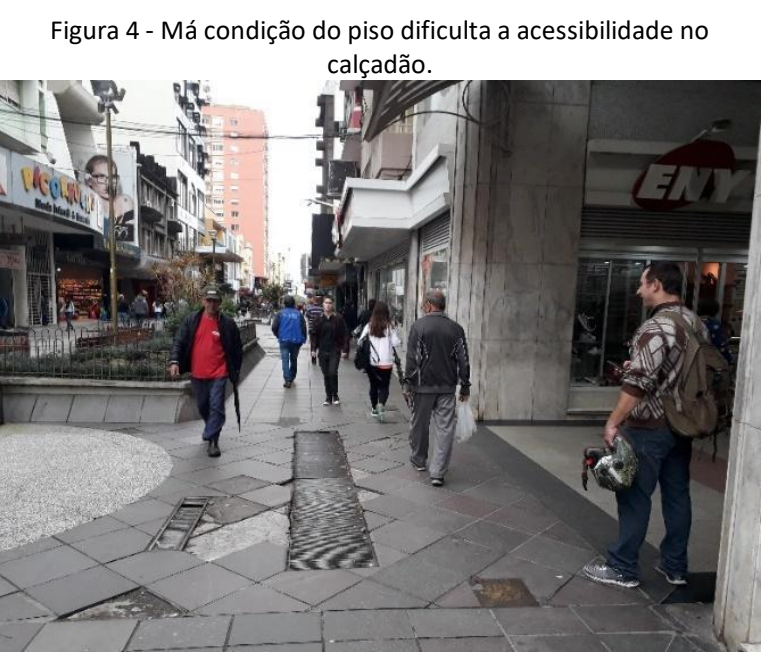

Fonte: Autores
Figura 5 - Más condições do piso na rua Dr. Bozzano.

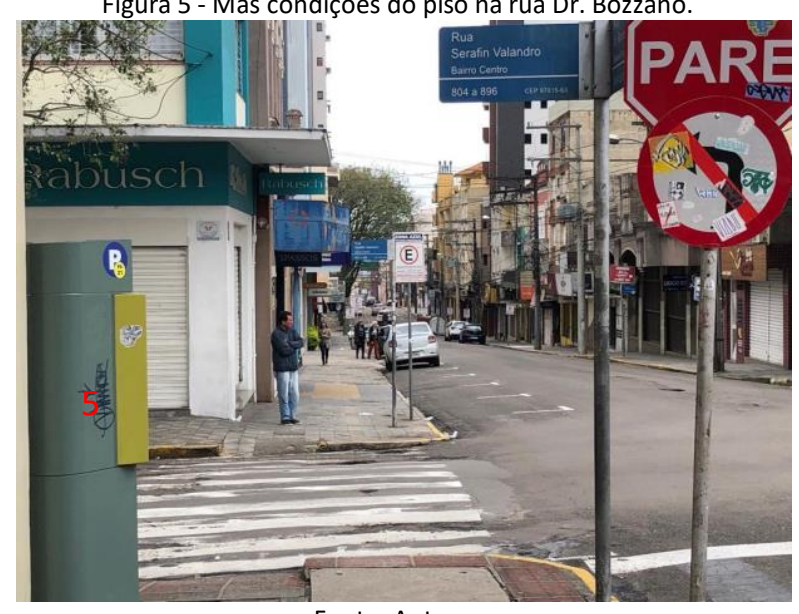

Fonte: Autores

Além disso, há pouco ou inexistente sombreamento natural; pouco ou inexistente mobiliário adequado e inclusivo (figura 5); áreas inseguras de uso por massificação de vandalismo e pela perda do pertencimento local (figura 6); falta de infraestrutura de apoio básica, como banheiros e bebedouros. 


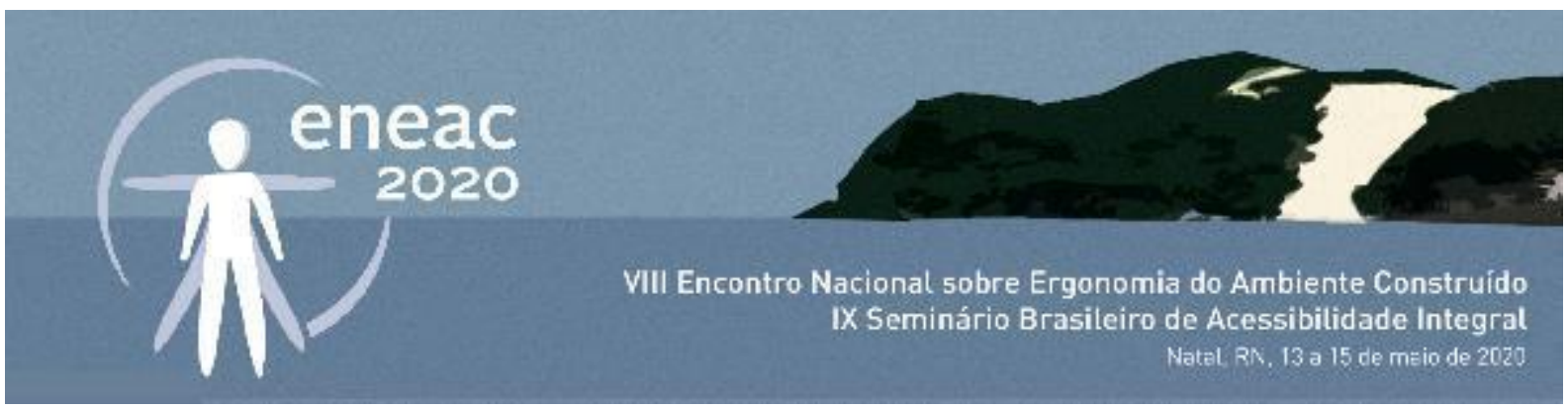

Figura 6 - Más condições do mobiliário na Praça Saturnino de Brito.

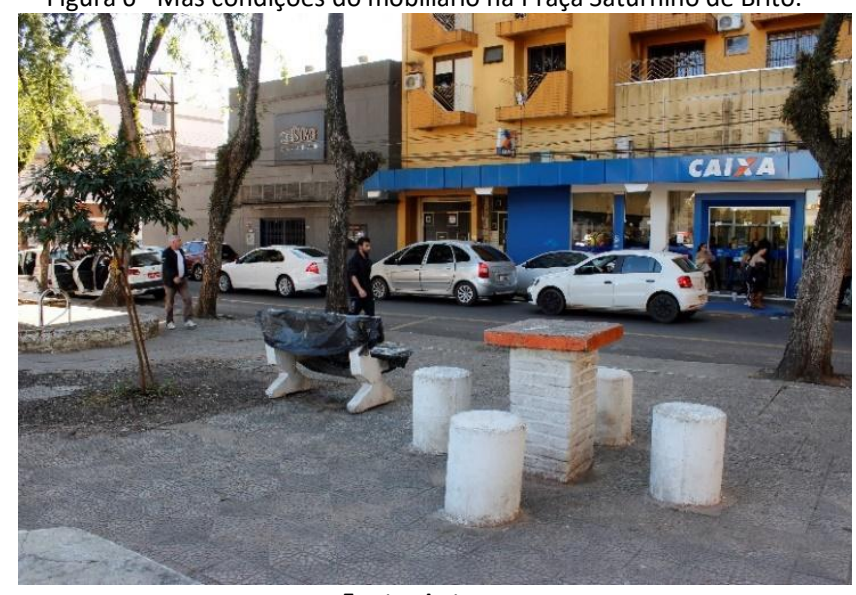

Fonte: Autores
Figura 7 - Na Praça Saturnino de Brito, não há apropriação dos usuários e a violência se propagou.

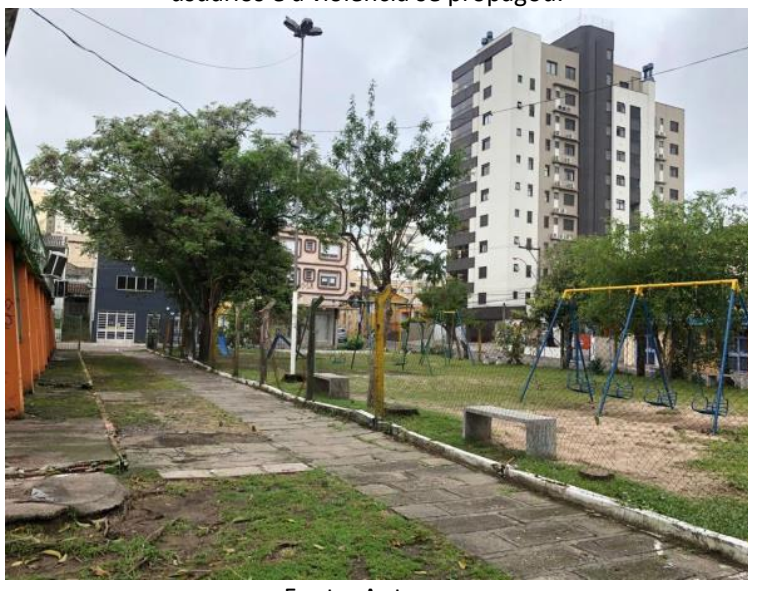

Fonte: Autores

Assim, através deste método pôde-se verificar a precariedade dos espaços avaliados de uma forma geral, com poucas qualidades identificadas, principalmente nos mobiliários, pavimentações e na falta de vegetação. Esses espaços acabam sendo evitados pela população devido a falta de infraestrutura adequada e a sensação de insegurança que sua falta de uso gera. A iluminação pública também é um aspecto a ser melhorado para promover maior apropriação dos locais.

\section{Entrevistas}

Na segunda metodologia, as entrevistas, foram entrevistadas 33 pessoas, sendo destas, $40 \%$ adultos jovens (entre 20 e 30 anos de idade) e 30\% adolescentes (entre 12 e 19 anos de idade). Quase 57\% das pessoas eram do gênero masculino. As pessoas foram escolhidas pelas entrevistadoras no local, tentando abranger todas as faixas etárias e escolaridade para se obter um resultado que abrangesse as necessidades de todos os possíveis usuários dos locais.

Cerca de $82 \%$ dos respondentes vão mais de 4 vezes por semana no centro. Grande parte por lazer, pelo comércio e por passagem. Como pode ser visto na figura 7, o espaço que mais gostam é a Praça Saldanha Marinho, por ser, como apontado por alguns entrevistados, amplo, democrático e, também, despertar boas lembranças de infância. 


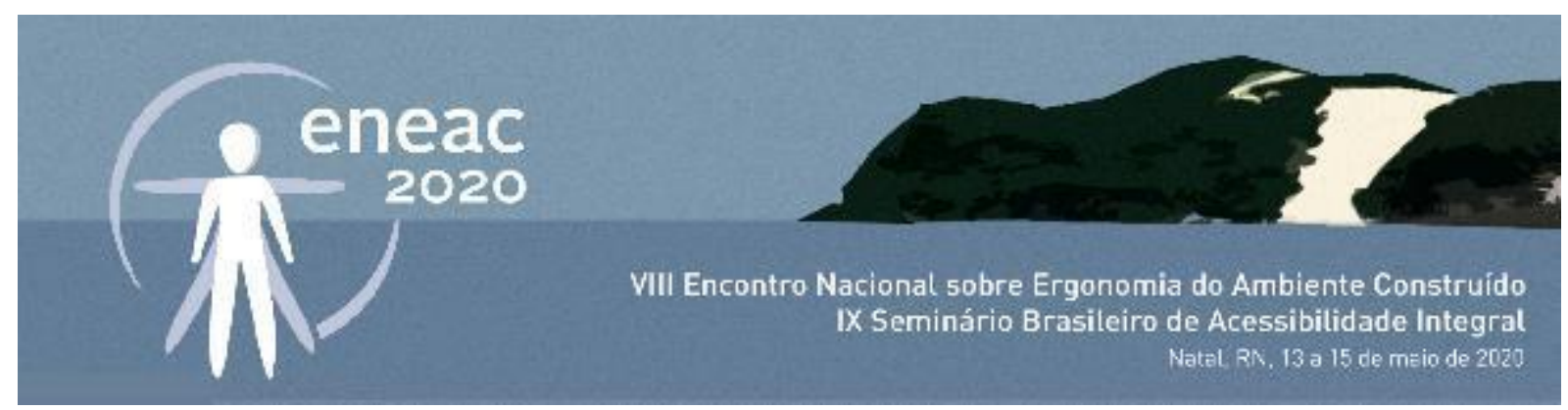

Figura 8 - Gráfico gerado através das respostas

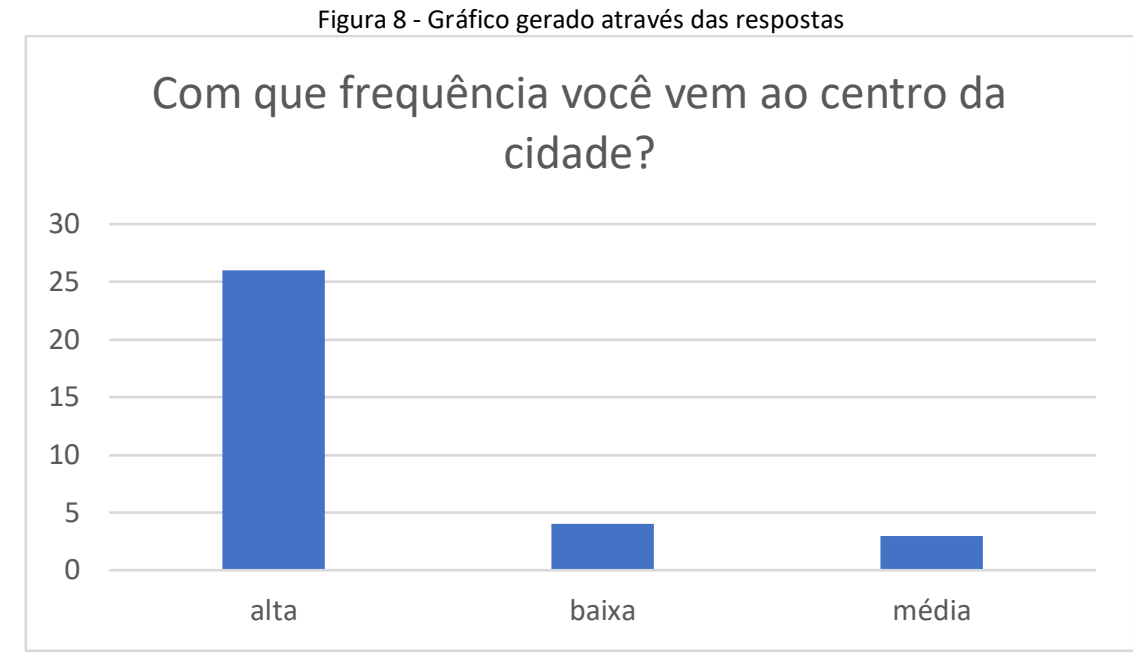

Fonte: Autores

Também percebeu-se, como se pode ver nas figuras 8 e 9, que grande parte das pessoas gostam do centro por sua identidade e qualidade do ambiente, porém, apontaram como aspectos negativos principais a falta de manutenção e segurança do local.

Figura 9 - Gráfico gerado através das respostas

Aspectos positivos relacionados ao centro.

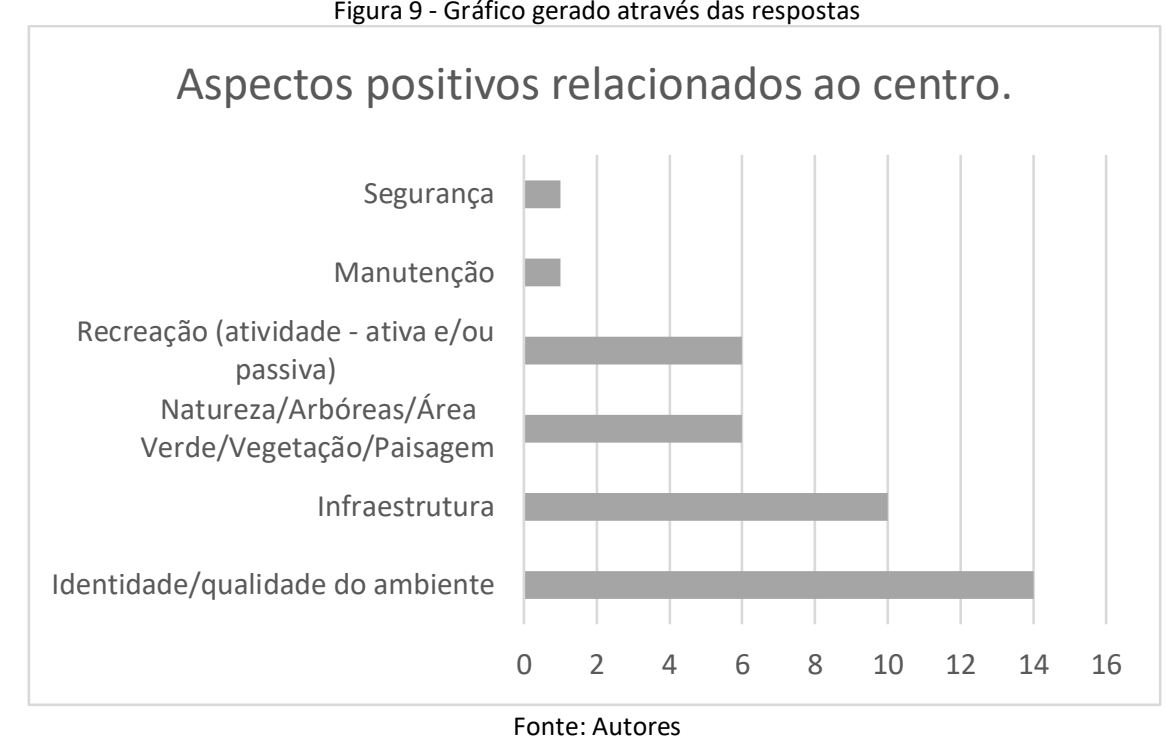




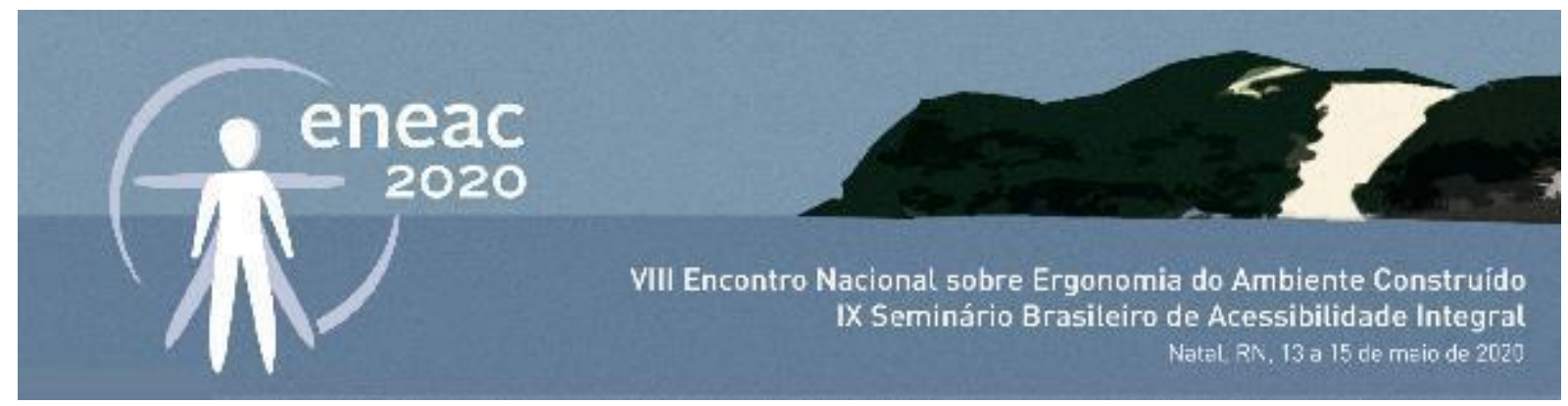

Figura 10 - Gráfico gerado através das respostas

\section{Aspectos negativos relacionados ao centro}

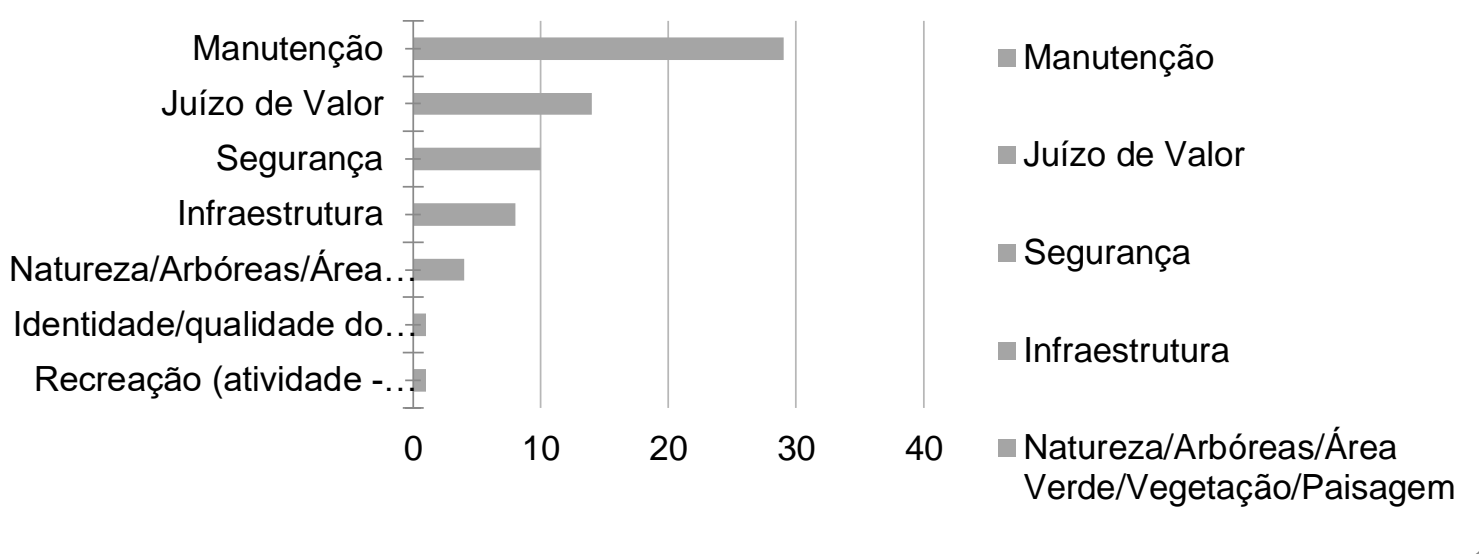

Fonte: Autores

Houve repetições nas falas de exemplificações de problemas locais referentes a pouca visibilidade entre diferentes pontos, sinalização confusa e presença de veículos estacionados nas vias que bloqueiam a visão. Além disso também foram indicados problemas como: más condições de piso, com suas irregularidades e barreiras; ausência de infraestrutura de apoio básica e mobiliários de uso não inclusivos e ergonômicos; excesso de poluição sonora e poucos espaços que estimulem a interação humana.

\section{Passeios Acompanhados}

Nos passeios acompanhados foi possível perceber, através da experiência assistida, que há carência em sinalização, as quais são confusas ou inexistentes, há muitas barreiras e grande fluxo de pessoas, o que pode dificultar uma caminhada mais fluída para todos os usuários. A seguir apresenta-se cada um dos passeios realizados:

No primeiro passeio realizado com uma pessoa em cadeira de rodas (ver figura 10), a dificuldade de locomoção ocorreu, principalmente, pela falta de manutenção de pavimento e pela inexistência ou ineficiência de rampas. A rampa da Galeria Chammi, por exemplo, possui inclinação extremamente acentuada e escadas, dificultando o acesso em cadeira de rodas à cafeteria. Na rua Doutor Bozzano, há muitos obstáculos próximos ao meio fio e, como há muito movimento de pedestres e as calçadas são estreitas, a locomoção sem paradas para descanso é dificultada. Como o passeio é estreito, os equipamentos que deveriam estar em uma faixa de serviço acabam por se tornar obstáculos. 


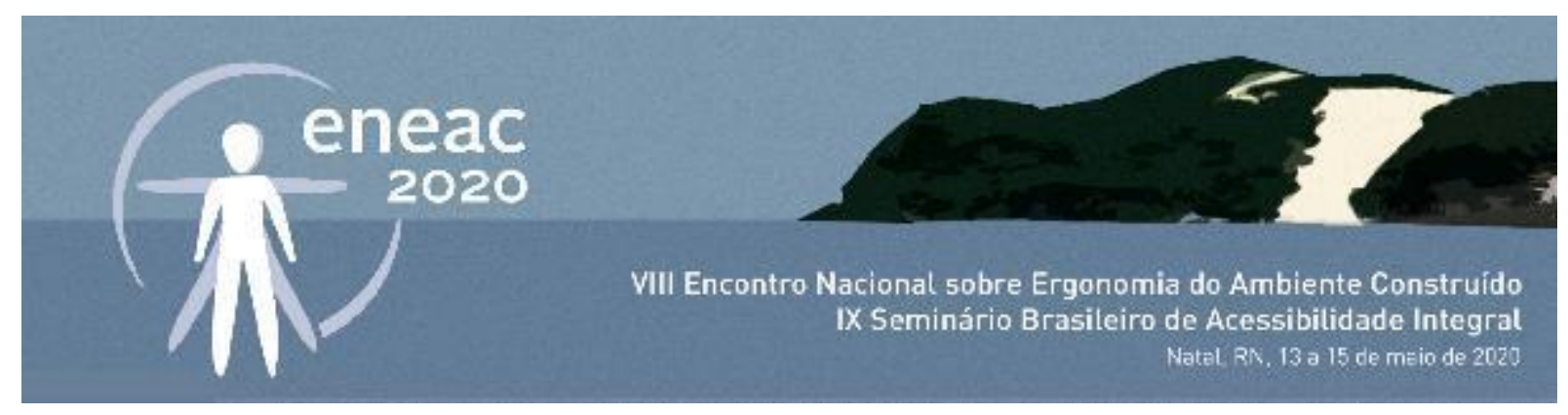

Figura 11 - Passeio acompanhado 1 - Pessoa em cadeira de rodas.

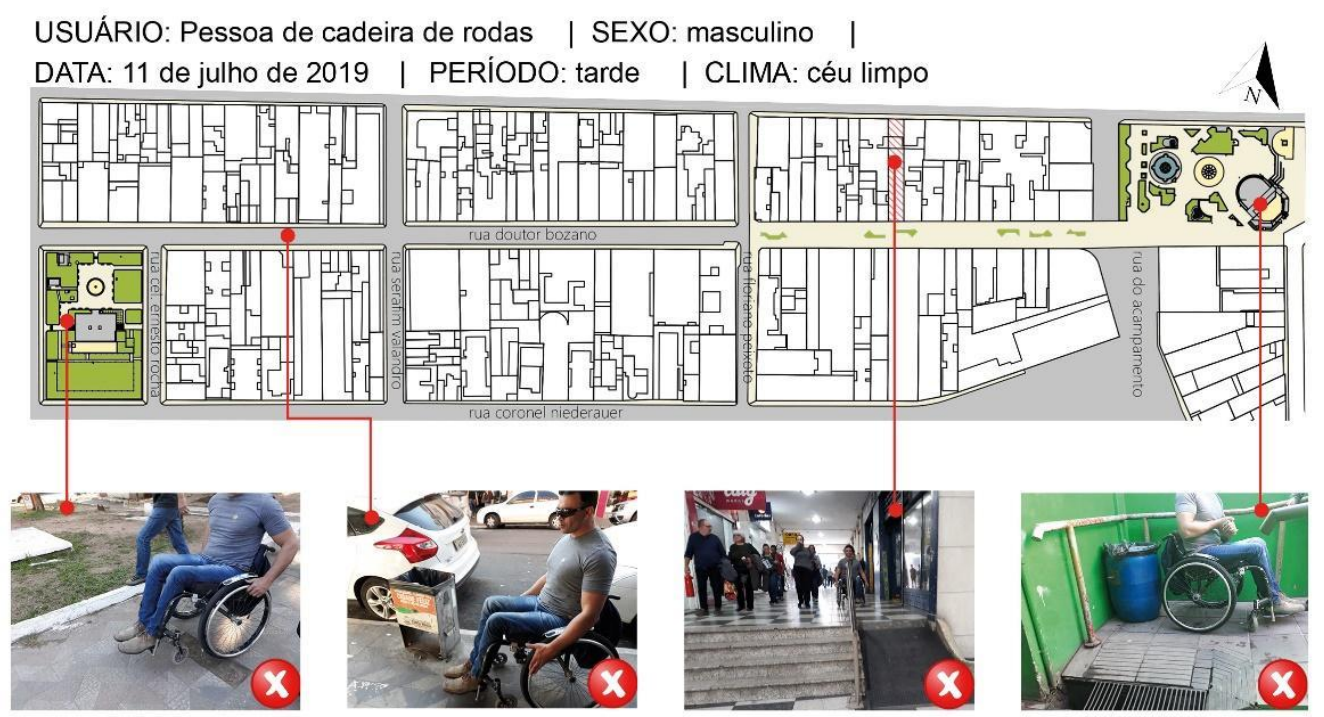

Fonte: Autores

No segundo passeio com a pessoa surdo-cega (figura 11), não houve muita dificuldade de locomoção pois a sua cegueira é noturna, ou seja, ela conseguia enxergar bem os obstáculos durante o passeio. Então ela foi apontando as dificuldades que teria se estivesse escuro.

Na galeria Chami não há piso tátil ou contraste de cor, nem sinalização adequada desses espaços. Também, foi exposta a dificuldade da visualização em função da falta de iluminação e pelo tipo de desenho do piso.

Figura 12 - Passeio acompanhado 2 - pessoa surdo-cega.

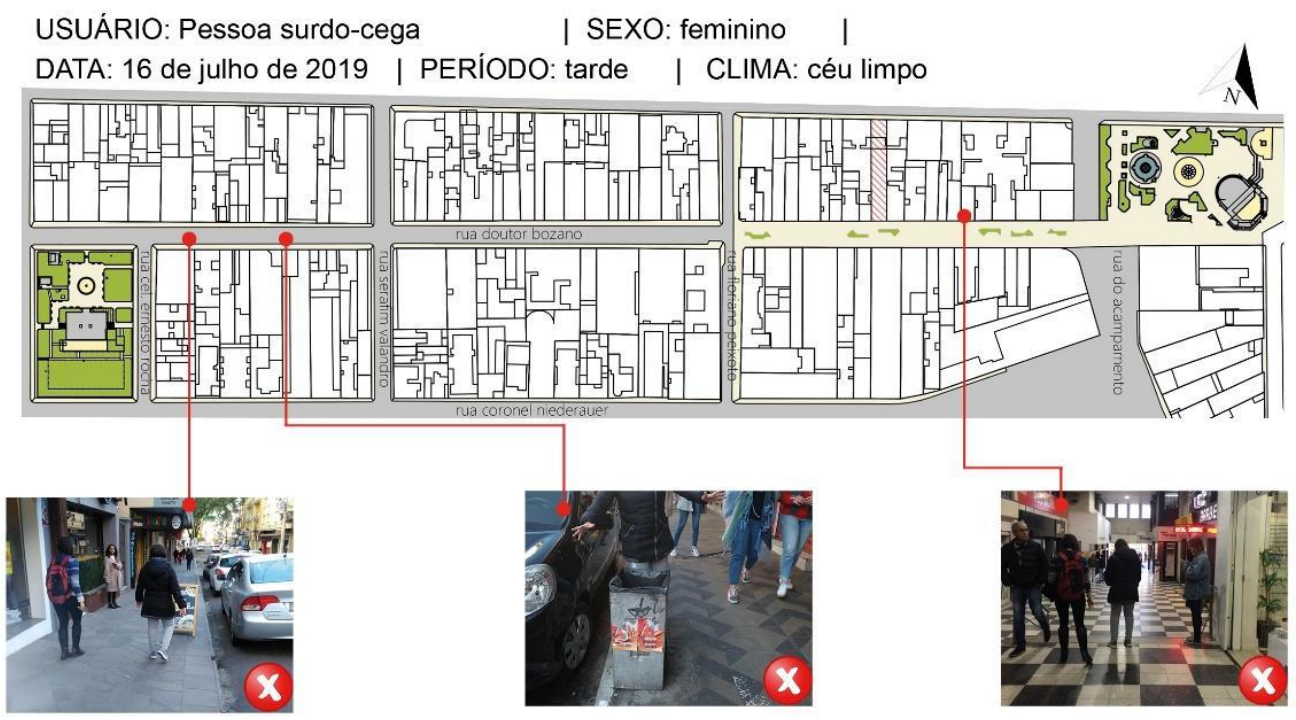




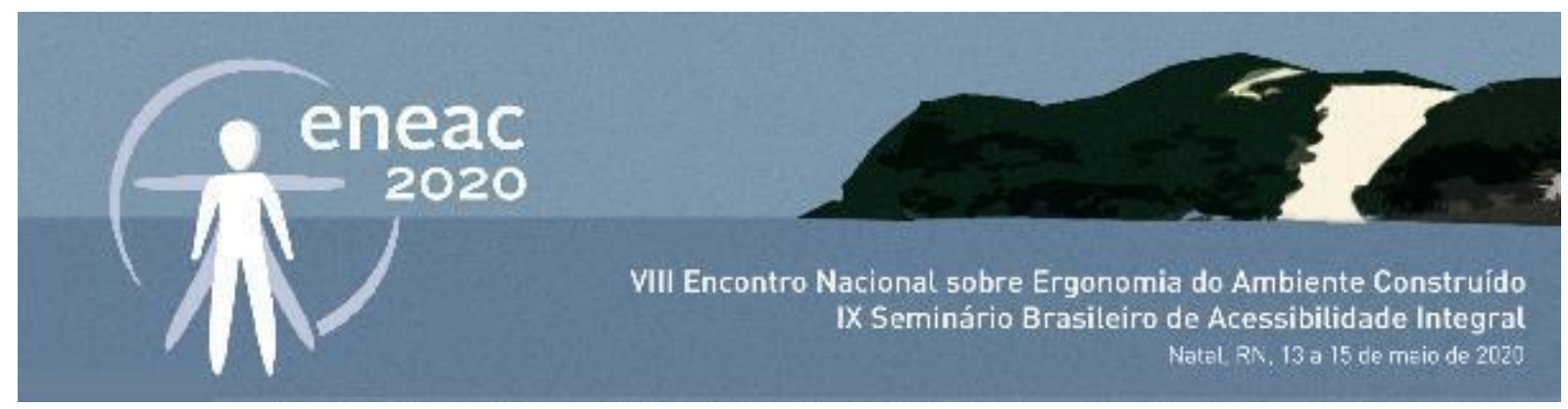

A pessoa cega, no terceiro passeio (figura 12 ), teve mais dificuldades em executar as atividades propostas sem que os pesquisadores explicassem como chegar aos locais. A falta de mapas táteis e piso tátil dificulta a orientação, assim, ele teve dificuldades para chegar aos locais propostos.

Ademais, a existência de barreiras atitudinais ou móveis e sem sinalização torna o percurso perigoso, por exemplo: logo ao chegar ao local de encontro marcado, ele deparou-se com um cactos próximo à parede cuja parte superior se projetava para o passeio e não podia ser identificado pela bengala na sua parte inferior (ver quarta foto da figura 12).

Foi identificado que a pessoa cega precisa se locomover tendo como referência as paredes das edificações do entorno ou utilizando seu conhecimento prévio do local e a falta de consideração dos outros acaba atrapalhando seus deslocamentos: "Como vocês viram, elas [as pessoas] não desviam. Elas tentam entrar na parede quando elas me enxergam." Em muitos casos, haviam pessoas apoiadas nas paredes, que não saíam quando viam que uma pessoa cega se aproximava por ela. Assim, elas se tornavam mais um obstáculo durante o percurso.

Outro aspecto que chamou a atenção durante a pesquisa foi a dificuldade em atravessar as ruas. Mesmo quando há sinaleiras, não há nenhum sinal sonoro que indique se o sinal está verde ou vermelho, então ele precisa guiar-se pelo barulho dos veículos, para saber se estão se aproximando ou não. Em um momento, quase foi atropelado por um carro.

Figura 13 - Passeio acompanhado 3 - pessoa cega.

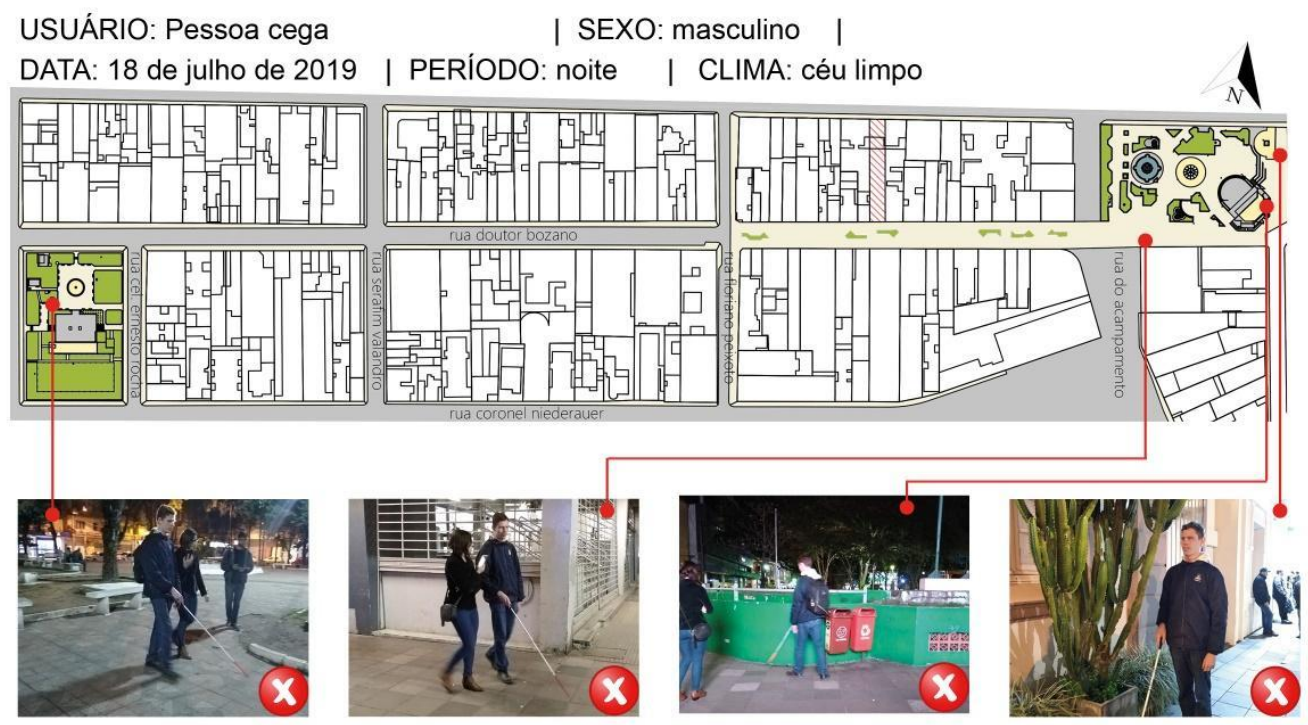

Fonte: Autores

O quarto e último passeio (figura 13) foi realizado com uma pessoa idosa. Ela não teve dificuldades em locomover-se. Porém, reclamou das condições de manutenção do local. 


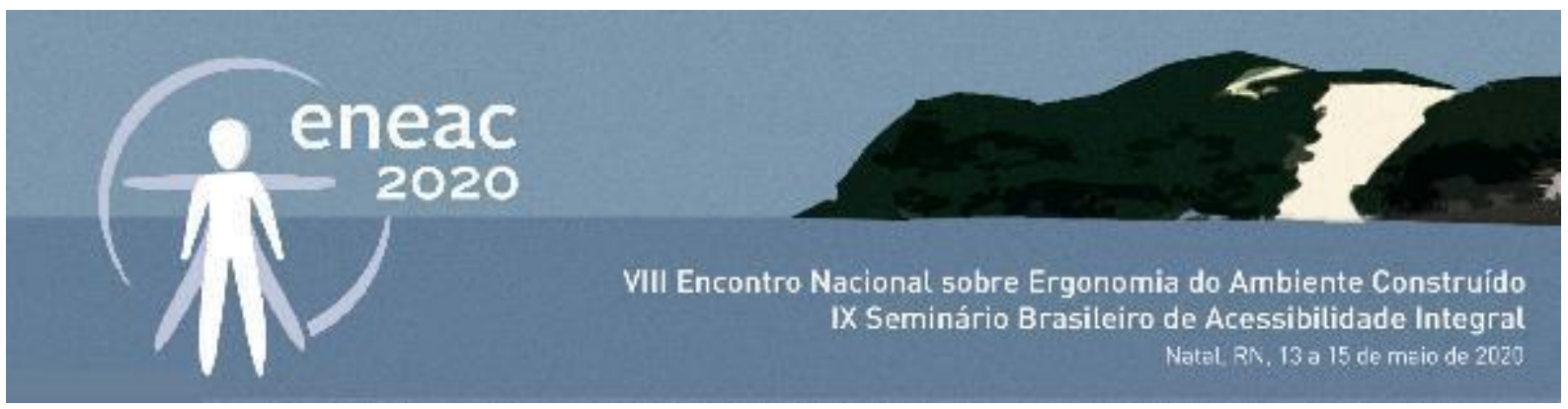

Figura 14 - Passeio acompanhado 4 - idoso.

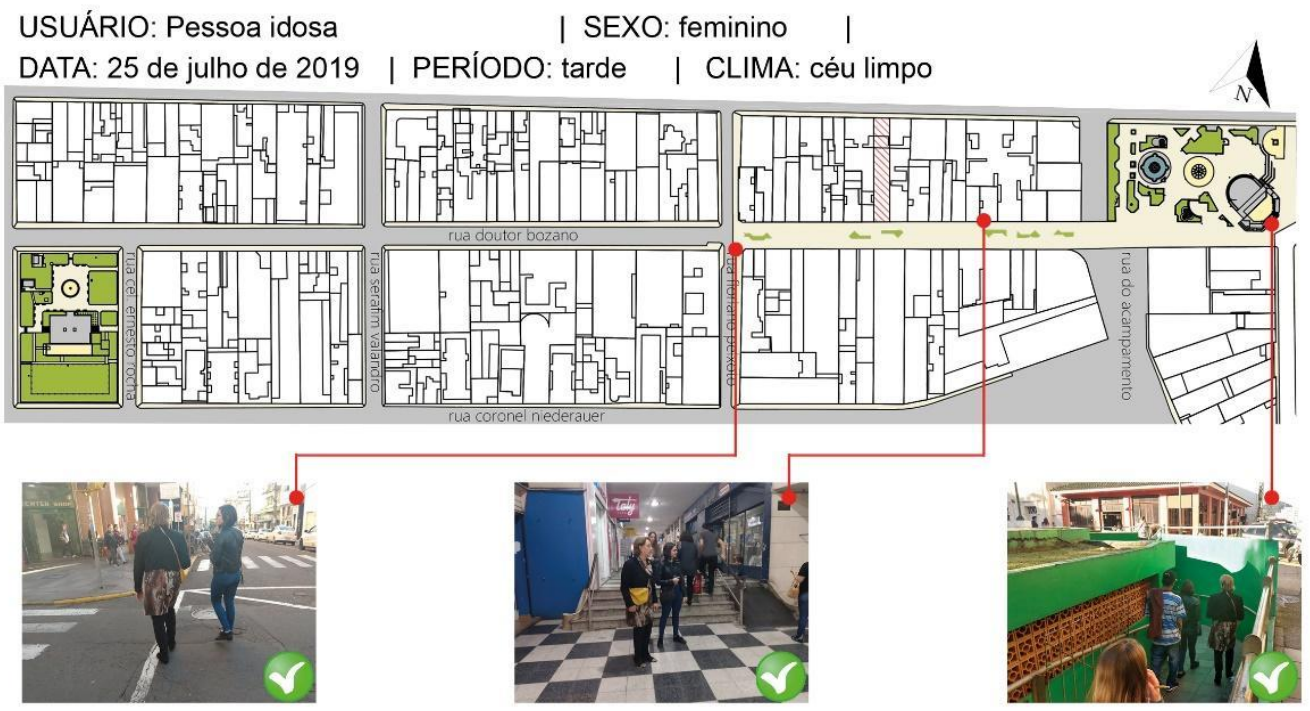

Fonte: Autores

Estes quatro passeios acompanhados permitiram uma visão geral das condições reais de acessibilidade nos locais analisados, e demonstrou a fragilidade dos espaços abertos do centro de Santa Maria para proporcionar a apropriação por pessoas com deficiência ou restrições.

\section{CONSIDERAÇÕES FINAIS}

A acessibilidade é importante para que se possa promover uma cidade com direitos iguais a todas as pessoas, além de garantir um espaço para interação com o ambiente, permitindo a identificação com o mesmo. Ao pensar-se em acessibilidade, leva-se em consideração pessoas com deficiências físicas, porém, é preciso considerar, também, que as pessoas envelhecem, e, ao envelhecerem, surgem outras restrições, cujas necessidades as cidades precisam suprir.

Desta forma, ao avaliar espaços urbanos sob a ótica da acessibilidade e do desenho universal para todas as pessoas, tem-se um diagnóstico para pensar como melhorar estes espaços e assim torná-los mais apropriáveis para todos. Vale ressaltar, ainda, que boa parte dos problemas encontrados com a metodologia adotada, para serem solucionados ou amenizados, demandam políticas públicas e educacionais.

O estudo de caso permitiu verificar que os espaços abertos do centro de Santa Maria ainda estão muito precários quanto as condições de acessibilidade. Do ponto de vista da comunicação, não há placas, mapas ou pisos táteis que possam colaborar com uma melhor apropriação de pessoas cegas, por exemplo, e quanto à orientação espacial, há problemas de visualização de um ponto para outro em função da presença de obstáculos visuais. Quanto ao deslocamento, há muitos momentos em que a pavimentação está inadequada, e que não há rampas ou essas possuem inclinação mais 


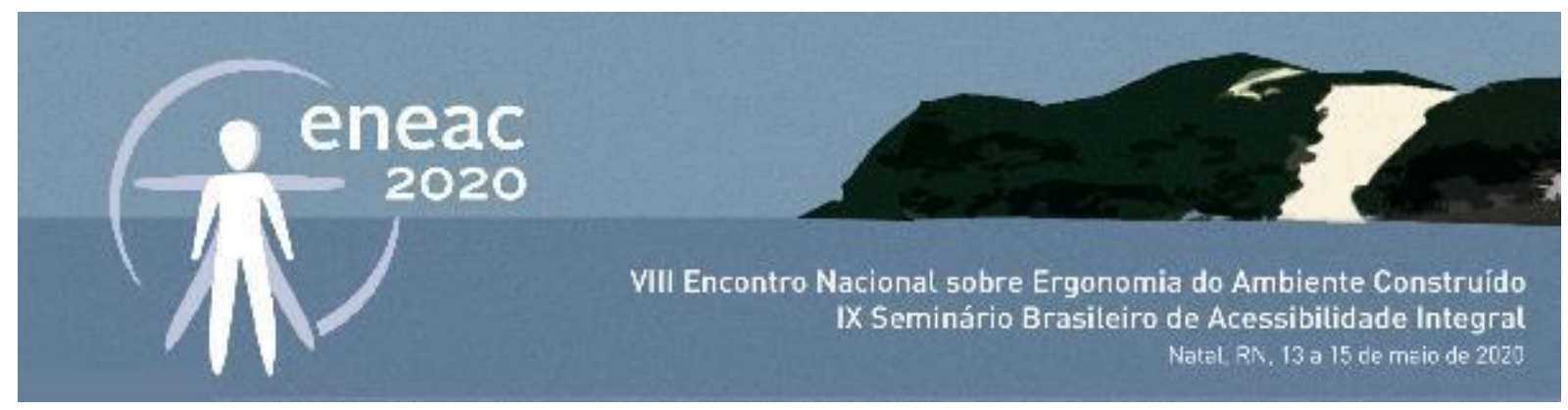

acentuada que a permitida. $\mathrm{O}$ uso nos locais também é dificultado pela precariedade dos mobilibiários, como bancos quebrados nas praças, além de ter seu acesso impossibilitado em alguns casos.

Assim, algumas diretrizes que poderiam ser adotadas nos espaços estudados para melhorar a apropriação seria: a implementação de mapas táteis nas praças, a adequação às normas dos pisos táteis e rampas, a manutenção da pavimentação, maior arborização nas vias e iluminação pública.

Esta pesquisa foi desenvolvida pensando em proporcionar, ao poder público municipal, subsídios para projetar e readequar os espaços abertos da cidade considerando às necessidades de diferentes usuários, sejam com deficiência ou não, e assim melhorar a apropriação do local, não do ponto de vista da quantidade, mas da qualidade.

\section{REFERÊNCIAS}

ASSOCIAÇÃO BRASILEIRA DE NORMAS TÉCNICAS ABNT. NBR 9050:2015. Acessibilidade a edificações, mobiliário, espaços e equipamentos urbanos. Rio de Janeiro: [s.n.].

BRASIL. Constituição da República Federativa do Brasil: texto constitucional promulgado em 5 de outubro de 1988, com as alterações determinadas pelas Emendas Constitucionais de Revisão nos 1 a 6/94, pelas Emendas Constitucionais nos 1/92 a 91/2016 e pelo Decreto . Brasília: Senado Federal, Coordenação de Edições Técnicas, 2016.

CAVALCANTE, S.; ELALI, G. A. Temas básicos em Psicologia Ambiental. Petrópolis: Ed. Vozes, 2017.

CAVALCANTE, S.; ELALI, G. A. Psicologia ambiental: Conceitos para a leitura da relação pessoa-ambiente. Petrópolis: Ed. Vozes, 2018.

DISCHINGER, M. Designing for all senses: accessible spaces for visually impaired citizens. Thesis (for the degree of Doctor of Phiolosophy) . Göteborg, Sweden: Department of Space and Process School of Architecture, Chalmers University of Technology, 2000.

DISCHINGER, M.; BINS ELY, V. H. M.; PIARDI, S. M. D. G. Promovendo a acessibilidade nos edifícios públicos: Programa de Acessibilidade às Pessoas com Deficiência ou Mobilidade Reduzida nas Edificações de Uso Público. Florianópolis: Ministério Público de Santa Catarina, 2013.

DORNELES, V. G. Estratégias de ensino de desenho universal para cursos de graduação em arquitetura e urbanismo. [Florianópolis.] Universidade Federal de Santa Catarina, 2014.

LÜDKE, M.; MARLI, E. D. A. A. Pesquisa em educação: abordagens qualitativas. São Paulo: EPU, 1986.

MACE, R. Universal Design, Barrier Free Environments for Everyone. Los Angeles: Designers West, 1985.

MACEDO, S. S. Espaços Livres. In: Paisagem Ambiente Ensaios 7, v. v7, p. p15- 56., 1995.

MENDONÇA, A.; BLOWER, H.; PÁSCOA, O. Creche Paulo Niemeyer: questões cognitivas. Brasil - Rio de Janeiro, RJ. Relatório da disciplina Avaliação de Desempenho do Ambiente Construído FAP 715.Rio de JaneiroPROARQ, FAU-UFRJ, , 2006. 